\title{
Soroepidemiologia da babesiose em rebanho de bovinos da raça Curraleiro
}

\author{
Seroepidemiology of babesiosis in Curraleiro cattle \\ Raquel Soares Juliano ${ }^{\text {I* }}$ Rosângela Zacarias MachadoII Maria Clorinda Soares Fioravanti ${ }^{\text {III }}$ \\ Gisele Maria AndradeII Valéria de Sá Jayme ${ }^{\text {III }}$
}

RESUMO

A babesiose bovina é uma hemoparasitose causada, no Brasil, pelos protozoários B. bovis e B. bigemina, as quais apresentam como único vetor biológico o carrapato Boophilus microplus. Foram avaliadas amostras dos animais da Estação Experimental de Estudos de Bovinos Curraleiros (EEEC) colhidas nos anos de 2001 (n=117) e 2003 (n=113). A detecção de anticorpos anti-B. bovis e anti-B. bigemina foi realizada pelo ELISA-indireto. $O$ objetivo deste trabalho foi estudar a soroepidemiologia da babesiose bovina em rebanho Curraleiro, obter informações sobre a situação da doença na população e relacionar os resultados obtidos com informações edafoclimáticas e de manejo disponíveis. A taxa de ocorrência em 2001 foi de 92,3\% para B. bovis e de 83,8\% para $\boldsymbol{B}$. bigemina e, em 2003, foi de 92,9 e 66,4\%, respectivamente. Houve diferença significativa na freqüência de soropositivos em relação à faixa etária no ano de 2003, ocorrendo uma diminuição com o avançar da idade. Sendo assim, foi possível concluir que, apesar das condições edafoclimáticas e do controle químico realizado no combate a ectoparasitas, os animais foram expostos à Babesia spp e encontravam-se em situação de estabilidade enzoótica para babesiose.

Palavras-chave: bovino, Babesia bovis, Babesia bigemina, estabilidade enzoótica, Pé-duro.

\section{ABSTRACT}

Bovine babesiosis is a blood parasitic disease. In Brazil it is caused by B. bovis and B. bigemina protozoa, both of which reveal the Boophilus microplus tick as the only biological vector. Animal samples were collected at Experimental Study Farm of Curraleiro Cattle (ESFC) in 2001 $(n=117)$ and $2003(n=113)$. The detection of antibodies against B. bovis and B. bigemina was carried out by ELISA-indirect method. This research was aimed at studing seroepidemiological aspects of bovine babesiosis in a Curraleiro herd, as well as obtain information about babesiosis stability in this population and relate the results with available climactic and management information. The occurrence rate of positive animals was $92.3 \%$ for $\boldsymbol{B}$. bovis and $83.8 \%$ for $\boldsymbol{B}$. bigemina in 2001; in 2003 it was $92.9 \%$ and $66.4 \%$, respectively. There was a significant difference between seropositive frequency and age in 2003; such a frequency decreased with ageing. It was possible to conclude that despite environmental conditions and chemical controls against endo and ectoparasites, these animals were exposed to Babesia spp and they found themselves in a situation of enzootic stability for babesiosis.

Key words: bovine animals, Babesia bovis, Babesia bigemina, enzootic stability, Pé-duro.

\section{INTRODUÇÃO}

No Brasil, a babesiose bovina é uma hemoparasitose causada pelos protozoários $\boldsymbol{B}$. bovis $\mathrm{e}$ B. bigemina, as quais apresentam como único vetor biológico o carrapato Boophilus microplus (GUGLIELMONE, 1995). Sua distribuição geográfica coincide com a área ocupada pelo vetor, ocorrendo entre os paralelos $32^{\circ} \mathrm{Ne} 32^{\circ} \mathrm{S}$, no continente americano, e a enfermidade apresenta uma importância econômica indiscutível, considerando-se o grande número de animais expostos ao risco de infecção nas regiões

\footnotetext{
IEmbrapa Pantanal (CPAP). Rua 21 de Setembro, 1880, CP 109, N.Srª de Fátima, 79320-900, Corumbá, MS, Brasil. E-mail: raquel@cpap.embrapa.br. Autor para correspondência.

"Faculdade de Ciências Agrárias e Veterinária (FCAV), Universidade Estadual Paulista Julio de Mesquita (UNESP), Jaboticabal, SP, Brasil.

"I'Escola de Veterinária, Universidade Federal de Goiás (UFG), Goiânia, GO, Brasil.
} 
tropicais e subtropicais e por apresentar elevada morbimortalidade em bovinos primo-infectados (SOLORIORIVERA\& RODRIGUEZ-VIVAS, 1997b).

Em áreas enzoóticas, os bezerros recémnascidos recebem anticorpos através do colostro, que os protegem durante os primeiros meses de vida. A exposição gradativa desses animais ao vetor e, conseqüentemente, ao parasito, é responsável pelo desenvolvimento da imunidade ativa, que resulta em menor ocorrência de casos clínicos de babesiose. Assim, a alta taxa de infecção, verificada pela soropositividade $\geq 75 \%$, em bezerros com idade de nove meses, caracteriza áreas de estabilidade enzoótica (MAHONEY, 1969; MAHONEY \& ROSS, 1972). A flutuação na população de B. microplus está relacionada às condições climáticas principalmente na fase de vida livre, e condições ambientais desfavoráveis determinam baixa infestação do hospedeiro vertebrado. Entretanto, em estudo realizado por Madruga e colaboradores, sobre a epidemiologia da tristeza parasitária, concluiu-se que, no Brasil, uma população reduzida de carrapatos é suficiente para manter a taxa de inoculação de hemoparasitas e a estabilidade enzoótica (LIMA et al., 2000).

Os estudos sorológicos são importantes não só para o monitoramento da babesiose, como para a adoção de estratégias adequadas de controle (SOLORIO-RIVERA\& RODRIGUEZ VIVAS, 1997b; OSAKI et al., 2002; SOUZA et al., 2002) e a detecção de anticorpos anti-Babesia spp pode ser realizada por diferentes testes sorológicos, sendo a reação de imunofluorescência indireta (RIFI) e o ELISA métodos sensíveis e específicos, que colaboraram para o avanço dos estudos epidemiológicos.

O gado que deu origem ao Curraleiro (Bos taurus ibericus), também conhecido como Pé-duro, foi trazido da Península Ibérica para o Brasil, pelos portugueses, na época do descobrimento, passou por um processo de seleção natural e adaptação às condições tropicais e, no século XX, com a introdução de raças bovinas exóticas, quase sofreu extinção (MARIANTE \& EGITO, 2002). Atualmente, animais desta raça estão presentes no Maranhão, no Piauí, em Goiás e em Tocantins. Os criadores ressaltam a rusticidade, o baixo custo de produção e a baixa exigência nutricional como qualidades indiscutíveis desses animais (NETESTADO, 1998). Existem poucas informações disponíveis sobre o rebanho nacional e a Associação Brasileira de Criadores de Curraleiro (ABCC) possui um cadastro, atualizado em março de 2005 , de 22 criatórios, com número estimado de 2.008 animais (BOAVENTURA et al., 2005). Não há estudos sobre as condições sanitárias desses rebanhos ou em relação à babesiose e aos elementos envolvidos na sua epidemiologia; somente relatos informais de criadores.

O objetivo deste trabalho foi estudar a soroepidemiologia da babesiose bovina no rebanho Curraleiro da EEEC (Estação Experimental de Estudos de Bovinos Curraleiros), discutindo os resultados obtidos com informações regionais sobre temperatura, pluviosidade, densidade populacional e controle químico para ectoparasitas realizados na propriedade.

\section{MATERIAL E MÉTODOS}

A EEEC é uma propriedade de 30.000 ha, com aproximadamente 800 ha ocupados pelo rebanho curraleiro, localizada na divisa dos Estados de MG, BA e GO. A região é caracterizada como bioma de Cerrado, mas seus limites territoriais estão próximos ao bioma da Caatinga. Em 2001, foram adquiridos um total de 162 animais, machos e fêmeas, com idades variando entre 12 e $\geq 48$ meses, provenientes de diferentes regiões do cerrado. Foram realizadas duas colheitas de sangue por venopunção jugular, o sangue foi centrifugado após retração do coágulo e o soro aliquotado e congelado a $-20^{\circ} \mathrm{C}$ até o momento da realização do teste sorológico. Em setembro de 2001, na primeira colheita, foram amostrados 117 animais, e uma segunda colheita foi feita em dezembro de 2003, quando foram amostrados 113 animais em uma população de 155 indivíduos.

A sorologia para detecção de anticorpos anti-Babesia bovis e anti-B. bigemina utilizou a técnica de ELISA-indireto, descrita por MACHADO et al. (1997), O antígeno de B. bovis foi obtido de um isolado do Rio Grande do Sul e o de B. bigemina de um isolado de Jaboticabal-SP, preparados segundo metodologia descrita por MACHADO et al. (1994).

As médias de temperatura foram fornecidas pelo Sistema de Meteorologia e Recursos Hídricos do Estado de Goiás (SIMEGO), obtidas na estação meteorológica de Flores de Goiás. A média pluviométrica ocorrida na EEEC foi obtida pelos registros da estação metereológica da propriedade, assim como as informações fornecidas pelo técnico responsável pelo rebanho sobre controle químico de ectoparasitas e lotação de pastagens.

Foram calculadas a taxa de ocorrência geral e a específica por faixa etária para os anos de $2001 \mathrm{e}$ 2003, utilizando-se as fórmulas descritas por THRUSFIELD (1995). Os resultados foram apresentados de forma descritiva e as freqüências comparadas pelo teste de qui-quadrado (SAMPAIO, 1998). 


\section{RESULTADOS E DISCUSSÃO}

$\mathrm{Na}$ tabela 1, foram apresentados os resultados de soropositivos para $\boldsymbol{B}$. bovis e $\boldsymbol{B}$. bigemina e verificou-se queda significativa $(\mathrm{P}<0,01)$ na porcentagem de soropositivos para $\boldsymbol{B}$. bigemina em 2003, porém a redução da positividade para B. bovis não foi significativa $(\mathrm{P}>0,01)$, comparando-se o mesmo período.

O sistema de criação desse rebanho era extensivo, com baixa lotação $\left( \pm 0,1 \mathrm{UA} \mathrm{ha}^{-1}\right)$ em pastagem nativa e campos sujos de Cerrado, que constituem o tipo de vegetação predominante na região Centro-Oeste, especialmente no Estado de Goiás. As médias máximas e mínimas de temperatura e precipitação pluviométrica, na estação seca (maio a setembro) e na chuvosa (outubro a abril), para os anos de 2001 a 2003, estão descritos na tabela 2. A estação chuvosa de 2002 apresentou altas temperaturas e baixa precipitação pluviométrica, seguida pela estação seca em 2003 com temperaturas altas e a menor precipitação de chuvas. Dessa forma, considerou-se que as condições ambientais de altas temperaturas, baixa umidade, cobertura vegetal escassa e baixa densidade populacional de hospedeiros vertebrados provavelmente interferiram no grau de infestação dos animais, o que está em concordância com FURLONG et al. (2002), que citaram que o sucesso do parasitismo é dependente de tais fatores.

As taxas de ocorrência verificadas no presente estudo foram inferiores às obtidas por SANTOS et al. (2001), no estudo realizado em rebanhos leiteiros da microrregião de Goiânia-GO, os quais relataram 98,9\% de positividade para B. bovis e 93,3\% para B. bigemina; entretanto, as condições ambientais, de lotação de pastagens, de manejo e as características raciais dos rebanhos eram muito diferentes da EEEC.

BARROS et al. (2005) encontraram uma porcentagem menor de positividade que o presente estudo, em municípios do semi-árido baiano, 63,7 e $53,0 \%$ para B. bovis e B. bigemina, respectivamente, em Uauá, 54,8 e 56,4\%, respectivamente, para as mesmas raças em Juazeiro. Este fato é compreensível, pois, apesar da semelhança nos registros de temperatura ambiente, os municípios avaliados apresentaram pluviometria e estação chuvosa menores que a EEEC. A diversidade número de soropositivos para cada região ocorre como conseqüência de variações climáticas, topográficas e no manejo dos rebanhos (SOLORIO-RIVERA \& RODRIGUEZ VIVAS, 1997b; OSAKI et al., 2002; SOUZA et al., 2002).

Os resultados da ocorrência de soropositivos para $\boldsymbol{B}$. bovis e $\boldsymbol{B}$. bigemina para cada faixa etária, nos anos de 2001 e 2003, estão descritos nas tabelas 3 e 4 , respectivamente. Foi possível verificar ocorrência de estabilidade enzoótica em 2001 e em 2003, tanto para B. bovis, quanto para B. bigemina, seguindo os critérios estabelecidos por MAHONEY (1969) e MAHONEY \& ROSS (1972). Tal característica significa que houve a inoculação gradativa do parasito resultando em imunidade ativa, o que explica a ausência de relatos de casos clínicos de babesiose.

O controle de ectoparasitos realizado na EEEC, recomendado pelo médico veterinário da propriedade, estabelecia o uso alternado de piretróides e organofosforados nos meses de março e novembro, apesar de constatar-se que a visualização de carrapatos adultos era incomum. Os bezerros recebiam ivermectina nos primeiros dias de vida para controle de miíase e os animais adultos nos meses de maio, julho e setembro para controle de endoparasitos. O controle químico de ectoparasitos e o uso da ivermectina não interferiram na condição de estabilidade enzoótica da população. VIEIRA et al. (2003) relataram que o uso de uma única aplicação de ivermectina $3,15 \%$ no mês de novembro determinou uma baixa infestação de carrapatos nos meses seguintes de janeiro, maio e setembro e diminuíram a taxa de infecção de B. bovis e B. bigemina, provocando condição de instabilidade enzoótica. Por isso, sugere-se, que apesar do uso da ivermectina não ter resultado em instabilidade enzoótica, ele pode ter contribuído para uma menor taxa de inoculação do parasito no rebanho da EEEC.

Tabela 1 - Número e freqüência de positividade para B. bovis e B bigemina em animais da raça Curraleiro, nos anos de 2001 e 2003 , utilizando teste de ELISA-indireto.

\begin{tabular}{|c|c|c|c|c|c|}
\hline Ano & $\mathrm{N}^{\mathrm{o}}$ de amostras & $\mathrm{N}^{\mathrm{o}}$ Positivos B. bovis & \% Positivos B. bovis & $\begin{array}{c}\mathrm{N}^{o} \text { Positivos } \boldsymbol{B} . \\
\text { bigemina }\end{array}$ & $\begin{array}{l}\% \text { Positivos } B . \\
\text { bigemina }\end{array}$ \\
\hline 2001 & 117 & 108 & $92,3 *$ & 98 & $83,8 * *$ \\
\hline 2003 & 113 & 105 & $92,9 *$ & 75 & $66,4 * *$ \\
\hline TOTAL & 230 & 213 & 92,6 & 175 & 76,1 \\
\hline
\end{tabular}

$* \chi^{2}=0,03 \mathrm{P}>0,01$ para $\boldsymbol{B}$. bovis.

$* * \chi^{2}=7,70 \mathrm{P}<0,01$ para B. bigemina.

Ciência Rural, v.37, n.5, set-out, 2007. 
Tabela 2 - Temperatura média registrada na região norte de Goiás e precipitação pluviométrica da Estação Experimental de Estudos de Bovinos Curraleiros, nos anos de 2001 a 2003.

\begin{tabular}{ccccc}
\hline \multirow{2}{*}{ Ano } & \multicolumn{2}{c}{$*$ Temperatura $\left({ }^{\circ} \mathrm{C}\right)$} & \multicolumn{2}{c}{ Precipitação pluviométrica $(\mathrm{mm})$} \\
\cline { 2 - 4 } & Estação seca & Estação chuvosa & Estação seca & Estação chuvosa \\
\hline 2001 & 15,5 a 34,7 & 19,9 a 35,2 & 10,0 & 193,3 \\
2002 & 15,9 a 35,3 & 21,3 a 34,7 & 23,5 & 183,3 \\
2003 & 17,2 a 34,5 & 21,1 a 35,1 & 5,2 & 192,3 \\
\hline
\end{tabular}

*Fonte: http://www.simego.sectecb.go.gov.br.

Considerando a porcentagem de soropositivos em relação à faixa etária, observou-se diferença significativa, no ano de 2003, para B. bovis $(\mathrm{P}<0,03)$, entre animais com 0 a 8 e 9 até 35 meses de idade, e para B. bigemina $(\mathrm{P}<0,01)$, a partir dos 36 meses de idade. Houve diminuição do número de animais positivos para ambas as espécies de Babesia spp com o avançar da idade, possivelmente relacionada à queda dos títulos de anticorpos. GELETA (2001) considerou a diminuição dos títulos de anticorpos anti-B. bovis e anti-B. bigemina em animais mais velhos como conseqüência da queda nas taxas de reinfecção dos animais, devido a flutuações no tamanho da população de carrapatos e à menor parasitemia causada por aumento na resistência do hospedeiro vertebrado. Essa hipótese não pôde ser verificada no presente estudo, e não há estudos sobre a infestação e o comportamento do vetor nessa região ou nesta raça.

A diferença entre o número de soropositivos para B. bovis e B. bigemina, considerando que todos os animais convivem no mesmo ambiente, sugere que houve algum fator relacionado ao hospedeiro vertebrado que interferiu mais intensamente na capacidade de inoculação de $\boldsymbol{B}$. bigemina pelo carrapato. Os mecanismos de resistência dos bovinos ao B. microplus incluem imunidade inata, celular e humoral, reações de hipersensibilidade imediata e tardia
(OBEREM, 1984). A taxa de inoculação pode diminuir em raças bovinas resistentes ao vetor; entretanto, isso parece ser menos definitivo para B. bovis. A resistência pode estar relacionada a um processo de seleção natural, pela exposição contínua aos vetores e agentes por eles transmitidos, situação comum em populações de raças nativas (SOLORIO-RIVERA \& RODRIGUEZ VIVAS, 1997a). Esta hipótese pode ser aplicável à raça Curraleiro, já que esses animais passaram por um processo de seleção natural de aproximadamente 500 anos. A investigação da dinâmica sazonal do $\boldsymbol{B}$. microplus e dos mecanismos de resistência da raça Curraleiro seriam muito importantes na elucidação das variáveis que interferem na epidemiologia da babesiose bovina, pois a relação entre infectividade, carga de carrapatos e soroprevalência é extremamente complexa, sendo que, na avaliação do grau de estabilidade da população, ocorre a interferência de variáveis relacionadas aos animais (soroconversão) ou às características da propriedade (ambiente, manejo e exposição ao vetor).

\section{CONCLUSÃO}

De acordo com os resultados encontrados, pode-se concluir que houve uma diminuição significativa na freqüência de soropositivos para $\boldsymbol{B}$.

Tabela 3 - Número e freqüência de anticorpos anti-Babesia bovis e anti-Babesia bigemina em bovinos Curraleiros de diferentes faixas etárias no ano de 2001.

\begin{tabular}{|c|c|c|c|c|c|}
\hline \multirow{2}{*}{ Idade (meses) } & \multirow{2}{*}{ Número de animais amostrados } & \multicolumn{2}{|c|}{ Positivos B. bovis } & \multicolumn{2}{|c|}{ Positivos B. bigemina } \\
\hline & & $\mathrm{N}^{\mathrm{o}}$ & $\%$ & $\mathrm{~N}^{\mathrm{o}}$ & $\%$ \\
\hline $12-23$ & 27 & 27 & $* 100,0$ & 23 & $* * 85,2$ \\
\hline $24-35$ & 26 & 21 & $* 80,8$ & 19 & $* * 73,1$ \\
\hline $36-47$ & 13 & 12 & $* 91,7$ & 13 & $* * 100,0$ \\
\hline 48 ou $>$ & 51 & 48 & $* 94,1$ & 43 & $* * 84,3$ \\
\hline Total & 117 & 108 & 92,3 & 98 & 83,7 \\
\hline
\end{tabular}

$* \chi^{2}=3,49 \mathrm{P}>0,01$ não-significativo para $\boldsymbol{B}$. bovis entre as idades.

$* * \chi^{2}=2,10 \mathrm{P}>0,01$ não-significativo para $\boldsymbol{B}$. bigemina entre as idades.

Ciência Rural, v.37, n.5, set-out, 2007. 
Tabela 4 - Número e freqüência de anticorpos anti-Babesia bovis e anti-Babesia bigemina em bovinos Curraleiros de diferentes faixas etárias no ano de 2003.

\begin{tabular}{|c|c|c|c|c|c|}
\hline \multirow{2}{*}{ Idade (meses) } & \multirow{2}{*}{ Número de animais amostrados } & \multicolumn{2}{|c|}{ Positivos B. bovis } & \multicolumn{2}{|c|}{ Positivos B. bigemina } \\
\hline & & $\mathrm{N}^{\mathrm{o}}$ & $\%$ & $\mathrm{~N}^{\mathrm{o}}$ & $\%$ \\
\hline $0-8$ & 11 & 8 & $* 72,7$ & 9 & 81,8 \\
\hline $9-11$ & 9 & 9 & $* 100,0$ & 9 & 100,0 \\
\hline $12-23$ & 12 & 12 & $* 100,0$ & 11 & 91,7 \\
\hline $24-35$ & 12 & 12 & $* 100,0$ & 10 & 83,3 \\
\hline $36-47$ & 18 & 17 & 94,4 & 11 & $* * 61,1$ \\
\hline 48 ou $>$ & 51 & 47 & 92,2 & 25 & $* * 49,0$ \\
\hline Total & 113 & 105 & 86,7 & 75 & 66,4 \\
\hline
\end{tabular}

$* \chi^{2}=8,81 \mathrm{P}<0,03$ significativo para $\boldsymbol{B}$. bovis entre as idades.

$* * \chi^{2}=15,61 \mathrm{P}<0,001$ significativo para $\boldsymbol{B}$. bigemina entre as idades.

bigemina, entre os anos de 2001 e 2003; porém, o rebanho apresentou situação de estabilidade enzoótica sem que houvesse interferência do controle químico realizado sobre esta condição. Com o avançar da idade, ocorreu uma queda na positividade para Babesia spp, com significância estatística somente para $\boldsymbol{B}$. bigemina A interação de fatores climáticos e ambientais, associados à interferência fisiológica da imunidade do hospedeiro vertebrado, pode ter sido determinante dessa situação na população.

\section{AGRADECIMENTOS}

Ao Conselho Nacional de Desenvolvimento Científico e Tecnológico ( $\mathrm{CNPq})$ e ao Ministério da Integração Nacional, pelo apoio financeiro que viabilizaram este trabalho.

\section{REFERÊNCIAS}

BARROS, S.L. et al. Serological survey of Babesia bovis, B bigemina and Anaplasma marginale antibodies in cattle from the semi-arid region os state of Bahia, Brazil, by enzyme-linked immunosorbent assays. Memórias do Instituto Oswaldo Cruz, Rio de Janeiro, v.100, n.6, p.613-617, 2005.

BOAVENTURA, V.M. et al. Gado Curraleiro: relação dos criadores e aspectos gerais da raça. Goiânia: Sebrae-GO, 2005. 80p.

FURLONG, J. et al. Comportamento e ecologia de larvas do carrapato Boophilus microplus em pastagem de Brachiaria decumbens. Brazilian Journal of Veterinary Research Animal Science, São Paulo, v.39, n.4, p.213-217, 2002.

GELETA, A.R. Antibody response to Babesia bovis and Babesia bigemina by vaccinated and unvaccinated cattle in an endemic area. 2001. 98f. Dissertação (Mestrado em Ciências Veterinárias) - Faculdade de Ciências Veterinárias da Universidade de Pretoria, Africa do Sul.

GUGLIELMONE, A.A. Epidemiology of babesiosis and anaplasmosis in South and Central America. Veterinary Parasitology, Amsterdan, v.57, p.109-119, 1995.
LIMA, W.S. et al. Seasonal variation of Boophilus microplus (Canestrini, 1887) (Acari: Ixodae) in cattle im Minas Gerais State, Brazil. Tropical Animal Health and Production, Edimbrugh, v.32, p.375-380, 2000

MACHADO, R.Z. et al. An enzyme-linked immnusorbent assay (ELISA) for the detection of antibodies against Babesia bovis in cattle. Veterinary Parasitology, Amsterdan, v.71, p.17-26, 1997.

MACHADO, R.Z. et al. Isolation of Babesia bigemina and Babesia bovis merozoites by amonium chloride lysis of infected erythrocytes. Brazilian Journal of Medical Biology Research, Ribeirão Preto, v.27, p.2591-2598, 1994.

MAHONEY, D.F. Bovine babesiosis: a study of concerned in transmission. Annals of Tropical Medicine and Parasitology, Jacksonville, v.63, n.1, p.1-14, 1969.

MAHONEY, D.F.; ROSS, D.R. Epizootiological factors in the control of bovine babesiosis. Australian Veterinary Journal, Brunswick, v.48, p.292-298, 1972.

MARIANTE, A.S.; EGITO, A.A. Animal genetic resources in Brazil: result of five centuries of natural selection, Theriogenology, Amsterdan, v.57, p.223-235, 2002.

NETESTADO. Animais adaptam-se bem às regiões secas. Acesso em: 26 nov. 2002. [online]. Disponível em: http:// www.estado.estadao.com.br/agricola/htm

OBEREM, P.T. The immunological basis of host resistance to ticks: a review. Journal of the South African Veterinary Association, v.55, n.4, p.215-217, 1984.

OSAKI, S.C. et al. Ocorrência de anticorpos anti-Babesia bovis e estudo sobre a infecção natural em bovinos da raça Nelore, na região de Umuarama, Paraná, Brasil. Revista Brasileira de Parasitologia Veterinária, v.11, n.2, p.77-83, 2002.

SAMPAIO, I.B.M. Estatística aplicada à experimentação animal. Belo Horizonte: Fundação de Ensino e Pesquisa em Medicina Veterinária e Zootecnia, 1998. 221p.

SANTOS, H.Q. et al. Estudo da prevalência de anticorpos antiBabesia bovis e anti-Babesia bigemina em bovinos de leite da

Ciência Rural, v.37, n.5, set-out, 2007. 
microrregião de Goiânia, determinada pelos testes de imunofluorescência inditeta e ELISA. Ciência Animal Brasileira, Goiânia, v.2, n.2, p.133-137, 2001.

SOLORIO-RIVERA, J.L.; RODRIGUEZ-VIVAS, R.I. Epidemiologia de la babesiosis bovina. I. Componentes epidemiológicos. Revista Biomédica, Mérida, v.8, n.1, p.3747, 1997a.

SOLORIO-RIVERA, J.L.; RODRIGUEZ-VIVAS, R.I. Epidemiologia de la babesiosis bovina. II. Indicadores epidemiológicos y elementos para el diseño de estrategias de control. Revista Biomédica, Mérida, v.8, n.2, p.95-105, 1997 b.
SOUZA, A.P. et al. Prevalência de anticorpos anti-Babesia em bovinos no planalto Norte de Santa Catarina. Revista Ciência Agroveterinária, Lages, v.1, n.1, p.21-23, 2002.

THRUSFIELD, M. Veterinary epidemiology. 2.ed. Oxford: Blackwell Science, 1995. 479p.

VIEIRA, M.I.B. et al. Estratégias de controle do carrapato Boophilus microplus (Canestrini, 1887) e influência na estabilidade enzoótica da babesiose bovina. Revista Brasileira de Parasitologia Veterinária, Rio de Janeiro, v.12, n.4, p.139-144, 2003. 